IMITATIONS OF LIFE: Cloning, heterosexuality and the human in Kazuo Ishiguro's Never Let Me Go

\title{
Rachel Carroll
}

There is something rather 'queer' about the protagonists of Kazuo Ishiguro's 2005 novel Never Let Me Go. Living outside of conventional family and kinship structures, they affirm a collective identity defined against those they term the 'normals' (Ishiguro, p. 94). Taught from childhood to understand their difference as categorical and as residing in their inability to reproduce, they are subject to the irrational prejudices of others; even those dedicated to their care struggle to conceal their revulsion, as a former guardian confesses: 'Is she afraid of you? We're all afraid of you. I myself had to fight back my dread of you almost every day' (Ishiguro, p. 264). In the face of such stigma, Ishiguro's protagonists are compelled to 'pass' in the world of 'normals'. However, strategies of assimilation cannot enable them to escape a fundamental condition of their existence: the denial of their right to agency and self-determination on the grounds of their status as less than human. If the protagonists of Never Let Me Go are perceived by others to be strange or suspect in other words, 'queer' in the commonplace sense - this can be attributed to their unconventional relationship to reproductive origin as human clones. However, I would argue that it is not the human status of the clone which is in question in this novel so much as the normative discourses which conspire to contest it. This article 
seeks to articulate one reader's intuition concerning the 'queer' plight of Ishiguro's protagonists: namely, that the discursive construction of the human clone as 'unnatural' and 'inhuman' is implicated in the imperatives of heteronormativity. In other words, I wish to suggest that their queerness is not merely 'commonplace' but that it also pertains to their non-normative heterosexuality; in this way, it is possible to consider Ishiguro's clones under the extended rubric of 'queer' in its theorised sense.

Recent evaluations of queer theory have, following Judith Butler in 'Critically Queer', sought to "affirm the contingency" (1993, p.230) of the term 'queer'. In 'What's Queer About Queer Studies Now?', David L. Eng, Judith Halberstam and José Esteban Muñoz suggest that the ongoing interrogation of the terms by which queer defines itself exemplifies queer theory's commitment to the unsettling of identity categories; they suggest that "what might be called the "subjectless" critique of queer studies disallows any posting of a proper subject of or object for the field by insisting that queer has no political referent' (2005, p. 3, emphasis in original). Elsewhere, in 'Queer Theory for Everyone', Sharon Marcus acknowledges tensions between 'inclusive' theorisations of the term (as exemplified in the 'subjectless' critique above) and a tendency to deploy 'queer' as a 'compact alternative to lesbian-gay-bisexual-transgender' (2005, p.196, emphasis in original); moreover, she notes that 'while queerness is supposed to signify the instability of all sexual identities ... there is little extant work on the queerness of those conventionally considered heterosexual' (Marcus, 2005, p.196, emphasis added). ${ }^{1}$ While the protagonists of Never Let Me Go - the narrator Kathy and her childhood friends Ruth and Tommy - are nominally heterosexual they are nevertheless at odds with 
heterosexual norms; more specifically, as the product of technologies of assisted reproduction but genetically engineered to be unable to reproduce, their relationship to reproductive sexuality is paradoxical. I would argue that Ishiguro's clones can be interpreted as embodying a heterosexual identity which is disempowered and marginalized by heteronormativity; as such they reveal the tensions and contradictions at work within and between heterosexuality as an institution and an identity. ${ }^{2}$ Cathy J. Cohen defines heteronormativity as consisting of 'both those localised practices and those centralised institutions which legitimise and privilege heterosexuality and heterosexual relationships as fundamental and 'natural' within society' (1997, p.440). However, she goes on to question 'the unchallenged assumption of a uniform heteronormativity from which all heterosexuals benefit' (Cohen, 1997, p. 452). This article does not intend to suggest an equivalence between the non-normative heterosexual and the homosexual; while an inclusive definition of the term 'queer' could encompass both, it would become problematic if it obscured the different ways in which they are subject to heteronormative institutions, practices and discourses. What this article seeks to do - in speculative and tentative fashion - is to investigate the possibility that Ishiguro's exploration of the contingency of human identity in Never Let Me Go has a significant, if oblique, relationship to heteronormative constructions of heterosexuality and the human. Textual motifs of 'passing' are central to my analysis of Ishiguro's novel; I wish to suggest that in its exploration of the 'imitation of life' Never Let Me Go prompts important questions about the discursive reproduction of the human as a contested category of identity. ${ }^{3}$ 


\section{Remembering to be human: childhood as institution}

In her comprehensive survey of fictional representations of human cloning, I Am The Other: Literary Negotiations of Human Cloning, Maria Aline Salgueiro Seabra Ferreia has described the fantasy of human cloning as 'focusing in a consummate way the widespread millennial anxieties that permeate contemporary literature, popular culture, science and medicine' (1995, p.3). Indeed, millennial motifs of futurity, catastrophe and apocalypse have traditionally characterised fictions of human cloning. Ferreira's study was published prior to the birth of Dolly, the genetically cloned sheep, at the Roslin Institute in Edinburgh, Scotland in 1996. Dolly provoked extensive scientific, political and ethical debate and renewed public unease about the implications of the new genetics and the now foreseeable prospect of human cloning. In this context, with its tremendous potential for the imaginative investigation of issues of genetic engineering, gestational origin and industrial application, it is all the more striking that Ishiguro's novel eschews the more sensational motifs of science fiction fantasy for a deeply disquieting rendering of normality.

Never Let Me Go - published in 2005 but located in 'the late 1990's' (Ishiguro, $\mathrm{np}$ ) - imagines the near past as speculative future. It depicts a recognisable and far from futuristic British cultural landscape but one in which the mass production of human clones in the service of therapeutic medical technology has become normalised. In an analysis of contemporary debates about the technologies of human cloning and their ethical implications, Finn Bowring has contextualised the emergence of a distinction between 'therapeutic' and 'reproductive' cloning: 
It is because treatments derived from embryonic stem cells are likely to require the production of human embryos by cloning, that scientists and politicians have popularised the distinction between 'therapeutic' and 'reproductive' cloning, and made strong moral and legal cases for prohibiting the latter (defined as implanting a cloned embryo in a woman's womb). (2004, p. 403)

This semantic distinction acts to discursively construct technologies of human cloning; to the degree that such a distinction serves political as well as ethical ends it is necessarily expedient and fraught with contradiction. The categorical distinction between 'therapeutic' and 'reproductive' cloning seeks to address anxieties about the use of human embryos in medical research but cannot conceal the fact that an element of reproduction is integral to all forms of cloning. 'Reproductive' cloning is defined in order to be outlawed but this term inadvertently reminds us of the position of human cloning within a spectrum of technologies of assisted reproduction, most of which are routinely 'naturalised' as serving the 'right to a child'. The problematic nature of the use of therapeutic ends to justify medical means is already apparent, in contemporary culture, in the controversial use of technologies of assisted reproduction to produce a child whose body will act as a resource for an ailing sibling. ${ }^{4}$ Never Let Me Go imagines a world in which genetically cloned embryos are not merely conceived but brought to term and lived existence. Moreover, it is a world in which the distinction between therapeutic and reproductive cloning has collapsed; the cloning depicted in the novel is both therapeutic and reproductive, in that fully developed cloned bodies are being produced in the service of medical science. As Miss Emily puts it in the dramatic 
denouement of the novel: " "However uncomfortable people were about your existence, their overwhelming concern was that their own children, their spouses, their parents, their friends, did not die from cancer, motor neurone disease, heart disease" ' (Ishiguro, p. 258). Ishiguro's novel is not concerned with speculation about the forms which this technology will take; the absence of engagement with currently contentious scientific developments only serves to reinforce the impression that this development is neither novel nor new. Indeed, it is a practice sufficiently entrenched to have generated its own counter-discourse which takes the form of a social reform movement advocating the humane treatment of cloned subjects: " "we demonstrated to the world that if students were reared in humane, cultivated environments, it was possible for them to grow to be as sensitive and intelligent as any ordinary human being" ' (Ishiguro, p. 256). However, this complex temporal context, in which a contemporary medical and ethical controversy is depicted as a past reality, is one which the reader must deduce from the narrative which relies not on controversial public histories but on subjective memories.

The first person narrative of Kathy $\mathrm{H}$. is dominated by memories of an institutionalised childhood at Hailsham, a residential school resembling a paternalistic orphanage: the pupil population at Hailsham is only gradually revealed to the reader as consisting of human clones. ${ }^{5}$ Kathy's memories reveal the indirect and insidious way in which she and her peers learn the truth about their origins and their fate; they are 'told and not told' (Ishiguro, p. 79) through a process of gradual and partial disclosure: 'It feels like I always knew ... in some vague way ... nothing came as a complete surprise. It was like we'd heard everything somewhere before' (Ishiguro, p. 81, emphasis in original). The reader is arguably placed in a similarly 
oblique position in relation to narrative knowledge: both 'told and not told', she must resort to the same speculative and deductive strategies as Kathy. The novel further insinuates the reader into its narrator's perspective by evoking narrative tropes of childhood experience which are recognisable and familiar; Never Let Me Go can be placed within a tradition of boarding school narratives in which the closed world of the school stands for the institution of childhood. In this way, the novel could be understood as a normalising narrative of human cloning. Indeed, the narrative evokes the peculiar idioms of childhood and young adulthood and their function in defining group and individual identities; here the identification of 'normals' (Ishiguro, p. 94) and later of 'possibles' (Ishiguro, p. 136). The struggle over prescribed and sequestered spaces - the sports pavilion, the pond, the lunch queue and all the 'hiding places, indoors and out: cupboards, nooks, bushes, hedges' (Ishiguro, p. 43) - recalls the ways in which child and teen identities are mapped out through peripheral social territories. The 'Exchanges' and 'Sales' (Ishiguro, p.16) which punctuate the Hailsham calendar and the shared dedication to the accumulation of personal " "collections" ' (Ishiguro, p. 38) are also recognisable as practices by which a subculture circulates its meanings.

However, the rituals of child and adolescent cultures are implicated in this novel in what is essentially an institution of biotechnological slavery. ${ }^{6}$ 'Normals' are the non-cloned humans to whom the Hailsham students are destined to donate their vital organs and 'possible' is the term given to the imagined human original from which the students have been generated. The quest for privacy evident in the struggle for personalised space is countered by the pedagogic and medical surveillance to which the students are subject to ensure their fitness for purpose. 
Finally, the 'Sales' and 'Exchanges' of used possessions by which the students are encouraged to construct their own identities only underline the commodified status of their condition. The clones are, to use Judith Butler's phrase, 'foreclosed from possibility' $(2004$, p. 31) by a genetic origin which determines that their human agency will be forfeited. ${ }^{7}$ The dramatic revelation with which the narrative culminates is not so much the identification of Kathy and her classmates as clones, however, but rather the disclosure of Hailsham's identity as a social experiment established to 'prove' the humanity of clones; the mystery of the fabled gallery in which students' art work is exhibited is revealed: " "We took away your art because we thought it would reveal your souls. Or to put it more finely, we did it to prove you had souls at all" ' (Ishiguro, p. 255, emphasis in original). In other words, Kathy's first person narrative culminates with a discovery that her very status as human is contested and that the childhood in which her sense of self is rooted was itself designed to conceal her contested status from her; " "we sheltered you during those years, and we gave you your childhoods" ' (Ishiguro, p.263).

Never Let Me Go generates an apprehension of what it is to discover that one's humanity has been called into question: what it is to find that one's memories, desires and aspirations are perceived to be suspect, inauthentic or illegitimate. Contemporary debate and speculation about the prospect of reproductive cloning reveals the way in which such beings, as 'copies' of human originals, challenge notions of the human, especially in relation to issues of individuality, authenticity and origin. In this context, Judith Butler's reflections, in her 2004 book Undoing Gender, are pertinent: 
It is the inhuman, the beyond human, the less than human, the border that secures the human in its ostensible reality. To be called a copy, to be called unreal, is one way in which one can be oppressed, but consider that it is more fundamental than that. To be oppressed means that you already exist as a subject of some kind, you are there as the visible and oppressed other for the master subject, as a possible or potential subject, but to be unreal is something else again. To be oppressed you must first become intelligible. To find that you are fundamentally unintelligible (indeed, that the laws of culture and of language find you to be an impossibility) is to find that you have not yet achieved access to the human, to find yourself speaking only and always as if you were human ... (p. 30. Emphasis added) Butler is exploring the implications of the heteronormative denial of the reality of homosexual existence and identity: the way in which this refusal to grant legitimacy or concede intelligibility reduces a category of beings to less than human status. What this passage begins to reveal, I would suggest, is the implication of presumptive heterosexuality in definitions of the human - and in the discourses of rights to which humans have a claim. Ishiguro's cloned protagonists are unintelligible both to themselves and to others; I wish to propose that the affective power of Never Let Me Go resides in its unsettling of the familiar intelligibility of heteronormative identities. The controversies prompted by the potential prospect of reproductive human cloning can be attributed in part to the ways in which it challenges the heterosexual prerogative to reproduction; in order to trace how a fiction of human cloning might give rise to questions of heteronormativity, I will 
foreground issues of reproduction and their relationship to normative constructions of heterosexuality.

Imitations of life: cloning and the reproduction of heterosexuality

When considered as a technology of assisted reproduction, cloning can be approached within the context of the extensive body of feminist scholarship on reproductive technologies. Feminist theorists have investigated these technologies, and their supporting discourses, in relation to gendered issues of power, agency and embodiment. ${ }^{8}$ Central to this work is a recognition of the paradoxes of power to which these technologies give rise. On the one hand, reproductive technologies can be understood as extending and consolidating the subjection of the female and maternal body to the patriarchal power of medical science. On the other, such technologies have the potential to empower women to exercise greater agency and control over their bodies and reproductive capacities. However, while these technologies reveal the extent to which conception, gestation and birth are not merely culturally mediated but increasingly culturally constructed, these interventions have been discursively enlisted to reinforce essentialist assumptions about women's relationship to maternity, most notably through the paradoxical renewal of naturalising discourses. As Dion Farquhar has written:

The ontology of "natural" biogenetic married heterosexual reproduction depended on its binary other of "unnatural" sterility (homosexuals, unmarried people, and so on.) Now, a new "other" to "natural" reproduction has been introduced by biotechnology - "artificial" donor- 
assisted asexual reproduction - and it must quickly work to erase its otherness . . by claiming its alliance with the "natural" - helping would-be parents have their "own" biogenetic child . . . (1995, p. 21)

The converse construction of infertility and childlessness as what Deborah Lynn Steinberg has called a 'pathological medical category' (1997, p. 41) only reinforces the normative effect of new reproductive technologies, extending the medicalisation of female bodies. Extending feminist frameworks of analysis to media representations of human cloning, Joan Haran, Jenny Kitzinger, Maureen McNeil and Kate O'Riordan have further explored the ways in which women's bodies are both visibly employed as 'normative signs' and rendered invisible as a material resource for cloning as 'a disembodied scientific practice' (2008, p.118).

Feminist work on reproductive technologies has focussed on their implications for women's agency and experience of embodiment. However, it is not only the 'naturalness' of gendered reproductive identity which is in question, I would argue, but also, if implicitly, the 'universality' of heterosexuality as the origin of reproduction. While the 'right to reproduce' is constructed in universalising terms, in practice it is reserved for those who conform to heterosexual norms; as Steinberg has demonstrated, with reference to access to In Vitro Fertilisation (IVF) screening, it is not heterosexuality per se which is privileged but more specifically its normative manifestations: 'heterosexuality is policed not only against the prospect of lesbian parenting, but indeed what are quite explicitly constructed as deviant familial heterosexualities (families without fathers)' $(1997$, p. 83). It could be argued that human cloning exponentially extends the challenge posed to heterosexuality as an institution by assisted reproduction; as Alan Petersen makes explicit in his analysis of 
news media coverage of the breakthroughs at the Roslin Institute: 'What seemed "unnatural" and "disturbing" to many people was the prospect of reproduction outside normative heterosexual arrangements' $(2002$, p. 81$) .{ }^{9}$ I would suggest that the heterosexual 'arrangements' that are at stake are not simply the sexual acts from which conception may result, and the relationships in which they take place, but also the social and cultural structures within which heterosexuality is implicated. Heterosexuality is a normative identity formation whose power is implicated in its capacity to pass unexamined; the 'impetus to render heterosexuality visible to critical scrutiny' (Johnson, 1997 p. 5) which characterises current work on heterosexuality could then be placed within a wider context of critical and theoretical frameworks, such as critical whiteness studies and masculinity studies, which seek to interrogate the 'unmarked' or 'invisible' nature of normative identities and their relationship to dominant modes of power. Lauren Berlant and Michael Warner evoke the ubiquitous and pervasive force of normative heterosexuality: Heteronormativity is more than ideology, or prejudice, or phobia against gays and lesbians; it is produced in almost every aspect of the forms and arrangements of social life: nationality, the state, and the law; commerce; medicine; and education; as well as in the conventions and affects of narrativity, romance, and other protected spaces of culture. (1998, p. 5545)

The specific 'arrangements of social life' which I wish to consider in Never Let Me Go are those concerning heteronormative structures of family and kinship.

The relationship between genetics, eugenics and kinship, and its implications for a critique of heteronormativity, is one which Deborah Lynn Steinberg has begun 
to examine. Steinberg suggests that eugenics can be seen as 'expressive, indeed productive, of a dominant discourse of family, that discourse of "legitimate" kinship in which class, gendered and racialised inequalities are normalised and in which heterosexuality is assumed and (re)inscribed' (1997, p. 75-6). Elsewhere, in a very suggestive formulation, Deborah Finkler argues that kinship organises human attachments through the production of "significant same" 'groupings who 'share instrumental, moral and affective codes that embrace feelings of obligations and responsibilities, which may be limited to one or more several generations of the living and the deceased' (1997, p. 15). In one sense, Ishiguro's clones constitute an alternative form of kinship; they are 'significantly same' to each other due to their shared memories and experiences. Hence Kathy admits her preference for other students from Hailsham: 'when you get a chance to choose, of course, you choose your own kind. That's natural' (Ishiguro, p. 4, emphasis added). However, their kinship is of a fragile constitution, rooted in memories of a place whose future is in jeopardy and motivated by the defensive vulnerability of those 'fearful of the world around us . . .unable quite to let each other go' (Ishiguro, p. 118). Moreover, their kinship lacks the legitimacy of a 'historical relation to futurity . . . to generational narrative and reproduction' (Berlant and Warner, 1998, p. 554) which heteronormativity privileges. As Never Let Me Go suggests, human cloning does not simply bypass conventional modes of human reproduction but produces a new category of being whose identity is not imbricated in heterosexuality as an institution. Nominally heterosexual, Kathy and her peers are nevertheless denied the privileges with which normative heterosexuality is rewarded; ${ }^{10}$ this can be attributed to the fact of their double alienation from reproductive norms, not only in 
terms of their origins outside of conventional structures of family and kinship but also in terms of their genetically engineered inability to sexually reproduce. Michael Warner alludes to this conflation of heterosexuality and reproduction in his discussion of 'reprosexuality' as:

an interweaving of heterosexuality, biological reproduction, cultural reproduction, and personal identity. . . Reprosexuality involves more than reproducing, more even than compulsory heterosexuality: it involves a relation to the self that finds its proper temporality and fulfilment in generational transmission. (1991, p. 9)

Outside of the generational narrative - without legitimate origin or reproductive legacy - the clone is expendable.

Unclaimed by their genetic kin and unable to generate their own kind, the clones are precluded from the networks of obligation and responsibility which define the 'significant same' according to Finkler; they suffer what Sarah Franklin has described as a 'genealogical shame' $\left(2007\right.$, p.26). ${ }^{11}$ And yet in other ways they uncannily mimic the 'sameness' which kinship privileges; genetically identical to their 'models' (Ishiguro, p. 37), they hold a mirror to the reproductive determinism of heteronormative kinship. Moreover, Kathy and her peers have been unknowingly schooled in assimilation; they are taught to 'pass' as normals within a culture which exploits them. I would suggest that this imitative motif serves less to reveal the inauthenticity of the cloned subjects than to demonstrate the performative and reiterative nature of normative heterosexuality. 


\section{Schooled to pass: performing and proving}

The location of a fiction of human cloning within the narrative context of an institutionalised childhood is significant in a number of ways. ${ }^{12}$ A residential school setting can signify either economic privilege or social marginalisation; belonging to the latter category, Hailsham's legacy in terms of childhood memory is comparable to that of other casualties of reproductive and familial norms: the abandoned, the illegitimate and the disabled child. Hailsham confirms the clones' location outside of the familial culture of reproductive sexuality and the world of what Kathy refers to as the 'ordinary family' (Ishiguro, pp. 157, 177, 214); furthermore, it provides an apt setting for a depiction of the totalising effect of heteronormative imperatives.

The trusting docility of Hailsham's pupils is suggestive of the successful internalisation of its regime; both within and beyond the school their lives are policed by 'unspoken' (Ishiguro, pp. 31; 121) and 'unwritten' (Ishiguro, p. 40) rules and agreements, many concerning what cannot be openly acknowledged. Of the gallery, Kathy recalls 'there was an unspoken rule that we should never even raise the subject in [the guardians] presence' (Ishiguro, p. 31) and yet she reflects that it 'it seems to me that this was a rule we imposed on ourselves, as much as anything the guardians had decided' (Ishiguro, p. 32). Significantly, Hailsham's residents remain 'students' long after graduation, readily assuming the role of pupil later in life: 'we gathered round to listen, the way we might have done at Hailsham when a guardian started to speak' (Ishiguro, p. 161). Moreover, in the disciplinary context of the classroom, the students are instructed in the inferiority of their identities. They are informed unambiguously that sex is more meaningful where it can result in 
conception and birth, something that none of them will experience; hence, their sexuality and desires are constructed as poor imitations of those of the 'normals': Then suddenly ... [Miss Emily] began telling us how we had to be careful about who we had sex with. Not just because of the diseases but because, she said, "sex affects emotions in ways you'd never expect." We had to be extremely careful about having sex in the outside world, especially with people who weren't students, because out there sex meant all sorts of things. Out there people were even fighting and killing each other over who had sex with whom. And the reason it meant so much - so much more than say, dancing or table tennis - was because the people out there were different from us students; they could have babies from sex. (Ishiguro, p. 82. Emphasis in original.)

Sexuality becomes less an expression of desire, attachment or pleasure than another social discourse which must be learnt and emulated for the purposes of integration. Hence Kathy's adolescent curiosity about sexuality seems not so much expressive of her emerging sexual identity as indicative of a struggle to understand a sexuality which is given no value: 'I also spent a lot of time re-reading passages from books where people had sex, going over the lines again and again, trying to tease out clues' (Ishiguro, p. 97, emphasis added). Her confessed interest in a discovered collection of pornographic magazines seems more studious than sexual; she discloses that she is searching for the face of her 'possible' having heard the rumour that the genetic models for clones are drawn from the socially marginalized and disempowered. As Ruth puts it: " "We're modelled from trash. Junkies, prostitutes, winos, tramps. Convicts maybe, just so long as they aren't psychos" ' (Ishiguro, p. 164). Kathy 
speculates that her sexual desires, unaccountable to herself in the context of a dominant reproductive matrix, must originate in the deviance of her genetic source: "It's just that sometimes, every now and again, I get these really strong feelings when I want to have sex. . . I don't know what it is, and afterwards, when it's passed over, it's just scary. That's why I started thinking, well, it has to come from somewhere. It must be to do with the way I am." (Ishiguro, p. 179).

Kathy's explanation for her interest in pornographic images offers another instance where an apparent imitation of conventional heterosexual behaviour reveals, instead, its contradictions. Indeed, performative motifs recur throughout the novel, with Kathy repeatedly finding herself an unwitting spectator or actor, positioned 'as if I was in the front row of the audience when [Ruth] was performing on stage' (Ishiguro, p. 128) or becoming like 'people in a play [Ruth] was watching' (Ishiguro, p. 216). In one of a number of uncanny moments which consist in the discovery of being watched or in the unwitting watching of others, Kathy finds herself under the tearful surveillance of Madame, the school's enigmatic visiting patron. She is acting out the lyrics to a favourite pop song - 'baby, baby, never let me go' (Ishiguro, p. 70) - by hugging an imaginary baby to her chest; in doing so, she appears to misunderstand the heterosexual vernacular of pop in assuming the 'baby' is an infant and not a lover. Madame's reaction, unfathomable at the time, would retrospectively seem to be a response to the futility of the fantasy, both in terms of motherhood and heterosexual identity. And yet Kathy's actions seem to be symptomatic of the imitative schooling which she and her peers receive, in which they are encouraged to mimic the behaviour of 'normals': a schooling which is itself 
symptomatic of a wider culture which obsessively rehearses heterosexual subject positions.

In this context, it is worth noting the particular significance with which the figure of the couple is invested in Never Let Me Go. One might expect the vagaries of romantic and sexual partnership to play a significant role in a narrative which dwells on adolescent group identities. However, coupledom is understood less as an elective expression of a romantic or sexual affinity than as a necessary assumption of a culturally coded set of practices: that is, as an index of successful assimilation into the world of the 'normals'. While staying at the Cottages, a transitional residence between Hailsham and the outside world, Kathy detects that some of the gestures and phrases by which older couples signify their status have been 'copied from the television' (Ishiguro, p. 118), including an American sitcom depiction of marital conflict: 'the way they gestured to each other, sat together on sofas, even the way they argued and stormed out of rooms' (Ishiguro, p. 119). Kathy recalls how her assiduously conformist friend Ruth is quick to act on these cues but also Ruth's impatience with her less socially apt partner, Tommy:

Anyway, my point is, it wasn't long before Ruth realised the way she'd been carrying on with Tommy was all wrong for the Cottages, and she set about changing how they did things in front of people... Mind you, at first, Tommy didn't have a clue what was going on, and would turn abruptly to Ruth and go: "What?", so that she'd have to glare furiously at him, like they were in a play and he'd forgotten his lines. I suppose she eventually had a word with him, because after a week or so they were managing to do it 
right, more or less exactly like veteran couples. (Ishiguro, p. 119. Emphasis added).

The myth of 'deferral', which dominates the closing stages of the narrative, becomes all the more poignant given that desires and attachments between students are credible only so far as they emulate those of 'normals.' Rumours circulate among students who have begun their work as donors and carers that a couple can be permitted to postpone donations, and hence defer 'completion' - the euphemism for premature death resulting from the loss of vital organs - if they can 'prove' they are in love. This belief is symptomatic both of the students' suggestibility and of the ruthless logic of heteronormativity. Kathy and Tommy are disabused of the myth of deferral - and of the myth of Hailsham - when they locate and confront its former patron, Madame, or Marie-Claude, in what they believe to be her home; motifs of 'performativity' and 'proof' converge to powerful effect in this scene. ${ }^{13}$

Kathy's attempts to orientate herself within the unfamiliar environment of a domestic interior are confounded by the sounds of unidentified movements and voices in other parts of the house; the very structure of the room in which she and Tommy wait seems to be in flux: 'The wall at the back of the room began to move. I saw almost immediately it wasn't really a wall, but a pair of sliding doors which you could use to section off the front half of what was otherwise one long room' (Ishiguro, p. 245). The awkwardness of Madame's movements and the rather charged tone of her address, combined with the sense of shifting spatial boundaries, create the impression of a staged encounter:

When we turned to sit down, she was over by the windows, in front of the heavy velvet curtains, holding us in a glare, like we were in class and she 
was a teacher ... Tommy, afterwards, said he thought she was about to burst into song, and that those curtains behind her would open, and instead of the street and the flat grassy expanse leading to the seafront, there'd be this big stage set. (Ishiguro, p. 246)

Moreover, Kathy discovers that she is not so much the spectator in this scene as an unwitting actor in a performance for an undisclosed audience: 'I realised, with a little chill, that these questions had never been for me, or for Tommy, but for someone else - someone listening behind us in the darkened half of the room' (Ishiguro, p 249). The revelation that Madame's rhetorical questions - " "Do I go too far?” “ (Ishiguro, p. 248) - are addressed not to Kathy but to the former Hailsham guardian Miss Emily, dramatically anticipates the subsequent revelation that Kathy's childhood was itself effectively 'staged' for another audience. As pupils at Hailsham, the students are encouraged to compete to produce art work for selection in Madame's gallery, unaware that their efforts are being exhibited as 'proof' of their humanity. As adults, Kathy and Tommy hope to 'prove' their love to Madame and Miss Emily in order to secure what is effectively a stay of execution; however, nothing that they are able to 'produce' can reverse the conditions of their identity. The students can no more enlist the reproductive logic of heterosexuality to 'prove' their love than can Hailsham 'prove' their humanity when heteronormative constructions of the human define them as inauthentic in advance. Hence the spurious logic of deferral reveals a more fundamental truth: that the exclusion of clones from the human right to self-determination is expressed through the deep implication of presumptions of heterosexuality in concepts of the human. 
In conclusion, Ferreira has noted the 'feelings of uncanniness' which often accompany fictional representations of human clones, referring to the 'reservoir of disquiet that many of these clone characters attempt to dispel by trying to build a life predicated, as much as possible, on normality ...' (1995, p. 35). However, the first person narrative of Never Let Me Go mitigates against the construction of the clone as 'other' to the reader; moreover, it is the implicitly normative status of the reader - which such 'othering' might serve to sanction - which is rendered uncanny by the narrative mode of address. In a recurring and poignant refrain, the narrator addresses the reader and wonders 'how it was where you were ...' (Ishiguro, pp 13; 67; 94). This direct address seems to interpellate the reader as a peer, a fellow graduate of an institutionalised childhood; while this might be read as further evidence of the discomforting naivety of the adult narrator it can equally be read as being suggestive of the way in which we are all schooled to 'pass' as normals. In an essay assessing current work in heterosexuality studies, Annette Schlichter has argued that 'it is crucial that we develop an understanding of heterosexual subjection as an overdetermined process of 'becoming straight' under the conditions of heteronormativity' (2004, p. 559). The peculiarity of the Hailsham regime reveals, in metaphorical fashion, the paradoxes and perversity of heteronormativity. The imitative schooling by which the clones are taught to pass as 'normals' reveals the performative nature of heteronormativity; nominally heterosexual in terms of their sexuality, the protagonists of Ishiguro's novel nevertheless suffer the penalties endured by those constructed as 'other' to the reproductive norm. Evidently, Never Let Me Go is not about heterosexuality in any explicit or exclusive way; indeed, readers of the novel may feel that, like Madame, I 'go too far' (Ishiguro, p. 248). But 
such is the normative nature of heterosexuality and its 'unmarked' or 'invisible' status that few cultural narratives could announce themselves in such a way. By reading Never Let Me Go as a narrative of passing within a heteronormative world, I have attempted to cast into relief the contradictions inherent in the conflation of reproductive sexuality and heterosexuality by heteronormativity; that is, to suggest that one effect of Ishiguro's uncanny fiction is to reveal the way in which heterosexuality as an institution both produces and penalises non-normative heterosexual identities. 
${ }^{1}$ Recent work on 'queer heterosexuality' offers one alignment of queer theory and heterosexuality; see Thomas (2000) and Fantina (2006). For a critical evaluation of this movement see Schlichter (2004).

${ }^{2}$ Stevi Jackson, for example, argues against “conflating heterosexuality as an institution with heterosexual practice, experience and identity' (1991, p.123).

${ }^{3}$ Linda Schlossberg, in her 'Introduction' to Passing: Identity and Interpretation in Sexuality, Race, and Religion, writes that 'heterosexual culture continually passes itself off as being merely natural, the undisputed and unmarked norm' (2001 p.5). Ishiguro's clones are heterosexuals who must nevertheless work hard to assume the 'unmarked' privileges of the norm / 'normals' (Ishiguro, p.94). ${ }^{4}$ I am referring here to the use of preimplantation genetic diagnosis (PGD) or tissue typing in IVF to produce a child whose umbilical cord, blood or bone marrow can be employed in the treatment of an existing sibling; such children have come to be known as 'saviour siblings'. I would suggest that Bowring's concerns about the fate of a genetically cloned child are arguably already applicable to the genetically engineered child: 'the respect, love and recognition ideally expressed by adults towards the child will be subverted by their expectation that they have ordered a predetermined product ...' (2004, p. 405, emphasis in original).

${ }^{5}$ In the context of a fictional memoir, the use of initials to abbreviate a character's surname may seem an act of narrative discretion; however, in Never Let Me Go it also indicates the absence of a patronym and of the family identity to which it refers.

${ }^{6}$ Margaret Everett makes an analogy with slavery in her discussion of the contemporary commodification of the gene: 'The commodification of the body is not a new phenomenon; slavery, prostitution and the sale of corpses, for example, attest to this fact' $(2003$, p. 58).

${ }^{7}$ Butler writes that 'If we are not recognizable, if there are no norms of recognition by which we are recognizable, then it is not possible to persist in one's own being, and we are not possible beings; we have been foreclosed from possibility' (2004, p. 31).

${ }^{8}$ See, for example, Franklin (1987), Kaplan and Squier (1999) and Stanworth (1997). 
${ }^{9}$ Moreover, Franklin describes as 'queer' Dolly the sheep's 'connections to sex and modes of reproduction' (2007, p. 46).

${ }^{10}$ Ruth and Tommy are former lovers and the more abiding bond between Kathy and Tommy finds expression when they become partners later in life. The Hailsham pupils are sufficiently entrenched in heteronormativity to have generated their own idiom for the insinuation of homosexuality: 'Gay sex, incidentally, was something we were even more confused about. For some reason, we called it "umbrella sex" ... I don't know how it was where you were, but at Hailsham we definitely weren't at all kind towards any sign of gay stuff' (Ishiguro, p. 94).

${ }^{11}$ Sarah Franklin attributes the anxiety with which 'illicit clones' are met directly to their relationship to genealogy: 'The dangerous illicit clone, its negativity doubled by both its figurative and historical associations, is generically and traditionally an abject embodiment of a particular kind of genealogical shame. Suspected of being a fake, a derivative, a copy, or a mere replicant, the clone is diminished by a lack of proper genealogy - and thus identity, substance, or origin' (2007 p. 26, emphasis added).

${ }^{12}$ Keith McDonald suggests that 'novels which depict schooling provide a fruitful forum by which the narrator's agency in a complex power structure can be framed, questioned, and understood' (2007, p.77).

${ }^{13}$ The house to which Kathy and Tommy follow Marie Claude appears also to be the home of Miss Emily; Marie Claude is a former colleague of, and seemingly a present carer for, Miss Emily, who attributes her use of a wheelchair to recent ill health. The possibility that the two women are a couple is one which does not seem to occur to Kathy.

\section{References}

Berlant, Lauren and Michael Warner. (1998) Sex in Public, Critical Inquiry, 24:2, pp. 547-567.

Bowring, Finn. (2004) Therapeutic and reproductive cloning: a critique, Social

Science \& Medicine, 58, pp. 401-409. 
Butler, Judith. (1993) Critically Queer, Bodies That Matter: On the Discursive Limits of "Sex". (New York and London: Routledge).

Butler, Judith. (2004) Undoing Gender (New York: Routledge).

Cohen, Cathy J. (1997) Punks, Bulldaggers, and Welfare Queens: The Radical Potential of Queer Politics? GLQ: Journal of Lesbian and Gay Studies, 3, pp. 437-65.

Elliott, David. (1998) Uniqueness, Individuality, and Human Cloning, Journal of Applied Philosophy, 15:3, pp. 218-230.

Eng, David L, Judith Halberstam and José Muñoz. (2005) Introduction: What's Queer About Queer Studies Now? Social Text 84-85, 23:3-4, pp. 1-17.

Everett, Margaret. (2003) The social life of genes: privacy, property and the new genetics, Social Science \& Medicine, 56, pp. 53-65.

Fantina, Richard, Ed. (2006) Straight Writ Queer: Non-normative expressions of heterosexuality in literature (Jefferson, North Carolina and London: McFarland \& Company).

Farquhar, Dion. (1999) Gamete Traffic / Pedestrian Crossings, in E. Ann Kaplan and Susan Squier (Eds), Playing Dolly: Technocultural Formations, Fantasies, \& Fictions of Assisted Reproduction (New Brunswick, New Jersey and London: Rutgers University Press).

Ferreira, Maria Aline Salgueiro Seabra. (1995) I Am The Other: Literary Negotiations of Human Cloning (Westport, Connecticut, London: Praeger).

Finkler, Kaja. (2000) Experiencing the New Genetics: Family and Kinship on the Medical Frontier (Philadelphia: University of Pennsylvania Press). 
Franklin, Sarah. (1987) Embodied Progress: a cultural account of assisted conception (London: Routledge).

Franklin, Sarah. (2007) Dolly Mixtures: The Remaking of Genealogy (Durham and London: Duke University Press).

Ishiguro, Kazuo. (2005) Never Let Me Go (London: Faber and Faber).

Jackson, Stevi. (1991) Heterosexuality in Question (London: Sage).

Johnson, Richard. (1997) Contested Borders, Contingent Lives: An Introduction, in Deborah Lynn Steinberg, Debbie Epstein and Richard Johnson (Eds), Border Patrols: Policing the Boundaries of Heterosexuality (London: Cassell).

Haran, Joan, Jenny Kitzinger, Maureen McNeil and Kate O’Riordan. (2008) Human Cloning in the Media: From science fiction to science practice (London and New York: Routledge).

Kaplan, E. Ann and Susan Squier, Eds. (1999) Playing Dolly: Technocultural Formations, Fantasies, \& Fictions of Assisted Reproduction (New Brunswick, New Jersey and London: Rutgers University Press).

Marcus, Sharon. (2005) Queer Theory for Everyone: A Review Essay, Signs. 31:1, pp. 191-218.

McDonald, Keith. (2007) Days of Past Futures: Kazuo Ishiguro's Never Let Me Go as 'speculative memoir', Biography, 30:1, pp. 74-83.

Petersen, Alan. (2002) Replicating our Bodies, Losing Our Selves: News Media Portrayals of Human Cloning in the Wake of Dolly, Body \& Society, 8:4, pp. 71-90. 
Schlichter, Annette. (2004) Queer at last? Straight Intellectuals and the Desire for Transgression, GLQ: Journal of Lesbian and Gay Studies, 10:4, pp. 543-564.

Schlossberg, Linda. (2001) Introduction, in María Carla Sánchez and Linda Schlossberg (Eds), Passing: Identity and Interpretation in Sexuality, Race and Religion. (New York: New York University Press).

Stanworth, Michelle, Ed. (1997) Reproductive Technologies: gender, motherhood and medicine (Cambridge: Polity).

Steinberg, Deborah Lynn. (1997) Bodies in Glass: genetics, eugenics, embryo ethics (Manchester: Manchester University Press).

Thomas, Calvin, Ed. (2000) Straight with a Twist: Queer Theory and the Subject of Heterosexuality (Urbana and Chicago: University of Illinois Press).

Warner, Michael. (1991) Introduction: Fear of a queer planet, Social Text, 29, pp. 317. 